\title{
Erratum to: Incorporating Uncertainty into a Life Cycle Assessment (LCA) Model of Short-Rotation Willow Biomass (Salix spp.) Crops
}

Jesse Caputo • Stephen B. Balogh • Timothy A. Volk • Leonard Johnson • Maureen Puettmann • Bruce Lippke • Elaine Oneil

Published online: 6 July 2013

(C) Springer Science+Business Media New York 2013

Erratum to: Bioenerg. Res.

DOI 10.1007/s12155-013-9347-y

The original publication of this article contained incorrect spelling of the 2nd author's name. It should be Stephen B. Balogh instead of Steven B. Balogh.

The online version of the original article can be found at http://dx.doi.org/ 10.1007/s12155-013-9347-y.

J. Caputo $(\bowtie) \cdot$ S. B. Balogh $\cdot$ T. A. Volk

Department of Forest and Natural Resources Management,

SUNY College of Environmental Science and Forestry,

1 Forestry Drive, Syracuse, NY 13210, USA

e-mail: jcaputo@syr.edu

L. Johnson

Leonard Johnson and Associates, 1205 Kamiaken Street,

Moscow, ID 83843, USA

M. Puettmann

Woodlife Environmental Consultants, LLC,

8200 NW Chaparral Drive, Corvallis, OR 97330, USA

B. Lippke $\cdot$ E. Oneil

College of the Environment, University of Washington,

Box 352100, Seattle, WA 98195, USA 